\title{
Studi Eksperimental Pengaruh Kemiringan Sudut Terhadap Alat Destilasi Air Laut Memanfaatkan Energi Matahari
}

\author{
C A Siregar ${ }^{1 *}$, A Marabdi Siregar ${ }^{2}$ \\ 1,2). Fakultas Teknik, Universitas Muhammadiyah Sumatera Utara \\ Jalan Kapten Mukhtar Basri No 3 Medan, 20238, Indonesia \\ *Email : chandra@umsu.ac.id
}

\begin{abstract}
Indonesia is one country that is in a tropical climate that promises sunshine of all time. The abundant potential of solar radiation can be utilized in a distillation device to convert sea water into fresh water. This research aims to build a distillation device as a provider of clean water. Test equipment is designed and built with black fiber material with a size of $1.25 \mathrm{~m} \times 0.8 \mathrm{~m}$ with a $3 \mathrm{~mm}$ thick glass cover with a capacity of $3600 \mathrm{ml}$ of sea water. To find out the effectiveness of the distillation apparatus, it was tested with three variations of slope angles namely $30^{\circ}, 40^{\circ}$, and $50^{\circ}$. Tests carried out in the city of Medan. The testing method is done by evaporating seawater, evaporation occurs because of the absorption of heat from the sun through a solar collector's plate. The result obtained an effective slope angle is $30^{\circ}$ with a production of $650 \mathrm{ml}$ of fresh water. In addition to fresh water production, it is also known that the maximum sea water temperature is $73^{\circ} \mathrm{C}$ at 12:20 WIB, the radiation heat transfer rate is $92.86 \mathrm{Watt}$.
\end{abstract}

Keywords: Distillation, Solar Radiation, Angle of Slope.

\section{PENDAHULUAN}

Indonesia merupakan negara dengan iklim tropis yang memiliki sinar/radiasi matahari yang berlimpah dan sangat menjanjikan. Hal ini mendasari bahwa seluruh wilayah/daerah yang berada di iklim tropis sangat berpotensi untuk memanfaatkan energi matahari sebagai sumber energi alternatif. Pemanfaatan energi matahari dapat dilakukan dengan 2 cara yakni konversi panas dan konversi pembangkit listrik tenaga surya (fotovoltaik). Namun, efektifitas konversi panas jauh besar mencapai $70 \%$, sedangkan fotovoltaik hanya mencapai 17\% [1].

Hal tersebut mendasari bahwa energi matahari yang dimanfaatkan sebagai konversi panas jauh lebih efektif daripada pemanfaatan secara fotovoltaik. Ada banyak inovasi teknologi yang memanfaatkan energi matahari seperti Solar Water Heater, sistem pengering hasil-hasil pertanian dan termasuk sistem destilasi. Destilasi merupakan istilah lain dari penyulingan untuk mendapatkan air bersih yang bersumber dari air asin maupun air kotor [2,3]. Sistem destilasi air laut ini, dilakukan dengan memanfaatkan sinar matahari untuk menguapkan air laut. Pada proses penyulingan terdapat proses perpindahan panas, penguapan, dan pengembunan Butiran-butiran uap yang tercipta tersebut merupakan air tawar yang tidak berbau dan tidak memiliki rasa [4].

Dalam penelitian ini, Alat destilasi surya yang akan diteliti berupa kolektor plat datar dengan fiber hitam dengan dimensi $1,25 \mathrm{~m} \times 0,8 \mathrm{~m}$, kaca penutup setebal $3 \mathrm{~mm}$. Berdasarkan penelitian sebelumnya, ditemukan bahwa jarak antara kaca penutup dengan fiber hitam yang efektif sebesar $15 \mathrm{~mm}$ [5]. Jarak kaca penutup dengan fiber hitam sebesar $15 \mathrm{~mm}$. Proses pengujian dilakukan dengan dengan tiga variasi kemiringan sudut yakni $30^{\circ}, 40^{\circ}$ dan $50^{\circ}$. Adapun tujuan dari penelitian ini adalah untuk mengetahui pengaruh kemiringan sudut terhadap efektifitas alat destilasi serta untuk mengetahui laju perpindahan panas yang terjadi pada alat destilasi. 


\title{
Jurnal Rekayasa Material, Manufaktur dan Energi http://jurnal.umsu.ac.id/index.php/RMME
}

\begin{abstract}
METODE PENELITIAN

\section{Rancangan Alat Uji}

Pada penelitian ini, alat destilasi yang dibangun dengan ukuran $1,25 \mathrm{~m} \times 0,8 \mathrm{~m}$. Alat ini terdiri dari 4 komponen utama yakni, fiber hitam, plat alumanium, kaca dan kerangka rangka alat. Pengujian sebelumnya menemukan bahwa Fiber hitam digunakan sebagai wadah air laut, pemilihan warna hitam dilakukan karena warna hitam merupakan warna yang memiliki kemampuan penyerapan panas yang baik. Plat alumanium diyakini mampu meningkatkan laju perpindahan panas [6]. Atas dasar tersebut, maka dilakukan penambahan plat alumanium disekeliling fiber hitam. Gambar 1 menunjukkan rancangan alat uji.
\end{abstract}

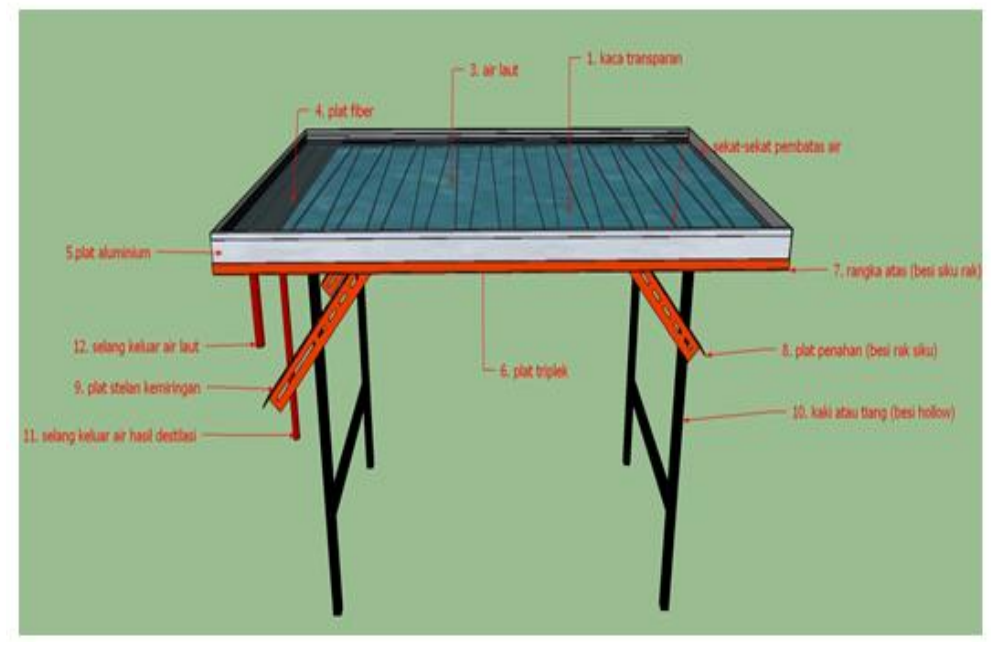

\author{
Keterangan: \\ 1. Kaca transparan \\ 2. Sekat-sekat pembatas air \\ 3. Air laut \\ 4. Plat fiber \\ 5. Plat aluminium \\ 6. Plat triplek \\ 7. Rangka atas (besi rak siku) \\ 8. Plat penahan (besi rak siku) \\ 9. Plat stel kemiringan \\ 10. Kaki atau tiang (besi hollow) \\ 11. Selang keluar air hasil destilasi \\ 12. Selang keluar air laut
}

\section{Gambar 1. Rancangan Alat Uji}

Pada bagian fiber hitam dengan $1023 \mathrm{~mm} \times 798 \mathrm{~mm} \times 10 \mathrm{~mm}$ dengan tebal $0.2 \mathrm{~mm}$, dibentuk sekat-sekat dengan jarak antara sekat yang satu dengan sekat lain nya adalah $50 \mathrm{~mm}$, dan tinggi sekat $10 \mathrm{~mm}$. Pembentukan sekat dilakukan dengan dengan menggunakan lem silicon yang daya tahan panasnya bisa mencapai $100^{\circ}-145^{\circ}$ derajat. Pembentukan sekat-sekat tersebut ditunjukkan pada gambar 2 . 


\section{Jurnal Rekayasa Material, Manufaktur dan Energi http://jurnal.umsu.ac.id/index.php/RMME}

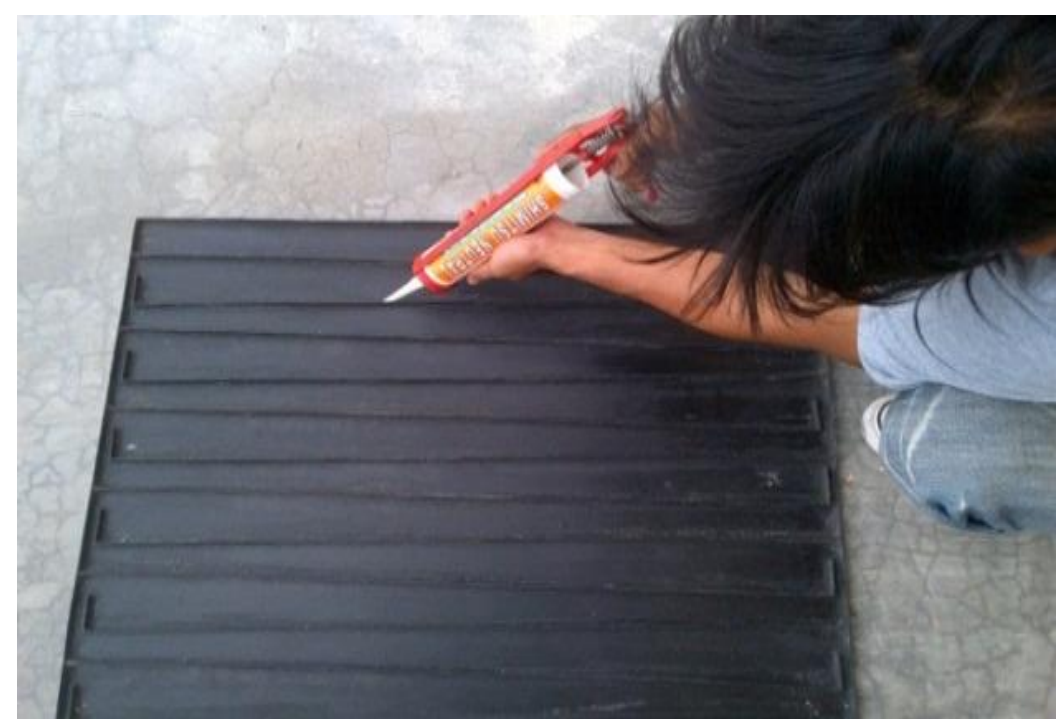

Gambar 2. Pembentukan sekat-sekat pada fiber hitam.

Sedangkan kemiriangan sudut, ditunjukkan pada gambar 3.

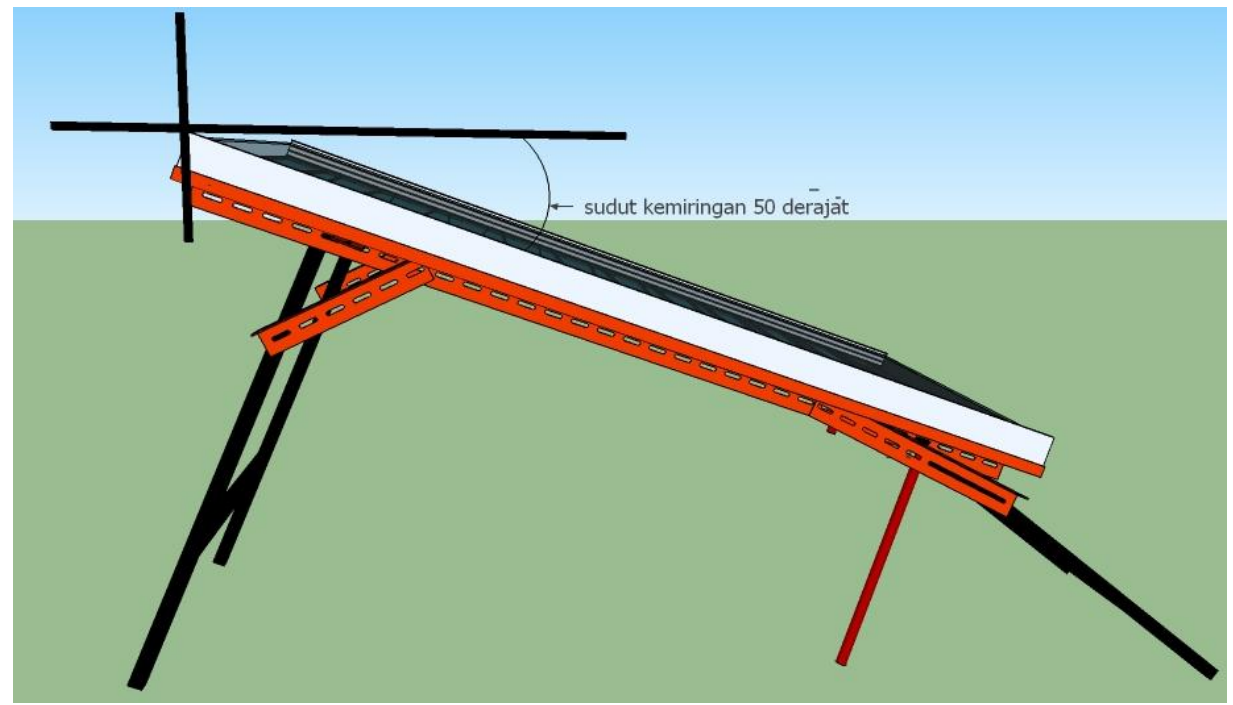

Gambar 3. Rancangan alat uji dengan kemiringan $50^{\circ}$.

Untuk mendapatkan data-data terkait perpindahan panas, pada rancangan alat uji juga dipasang alat ukur temperatur dengan rincian, lingkungan (Ta), permukaan kaca $(\mathrm{Tg})$, ruang basin (Tsv), Temperatur air laut di ruang basin yang lebih tinggi $\left(\mathrm{Tw}_{1}\right)$ dan Temperatur air laut di ruang basin yang lebih rendah $\left(\mathrm{Tw}_{2}\right)$. 


\section{Jurnal Rekayasa Material, Manufaktur dan Energi http://jurnal.umsu.ac.id/index.php/RMME}

\section{Pengujian dan Pengambilan Data}

Proses pengujian dan pengambilan data dilakukan pada pukul 11.00 - 14.00 wib selama 3 hari berturut-turut. Pengambilan data pada pukul 11.00 - 14.00 wib dilakukan karena pada jam tersebut merupakan puncak dari radiasi matahari yang sampai ke bumi. Pencatatan data dilakukan selama 30 menit sekali. Data - data yang terkumpul akan dianalisa secara teoritis dengan menggunakan persamaan-persamaan yang relevan. Pada akhir pengujian akan dilakukan pengukuran jumlah air bersih yang dihasilkan dalam satu kali pengujian dengan gelas ukur.

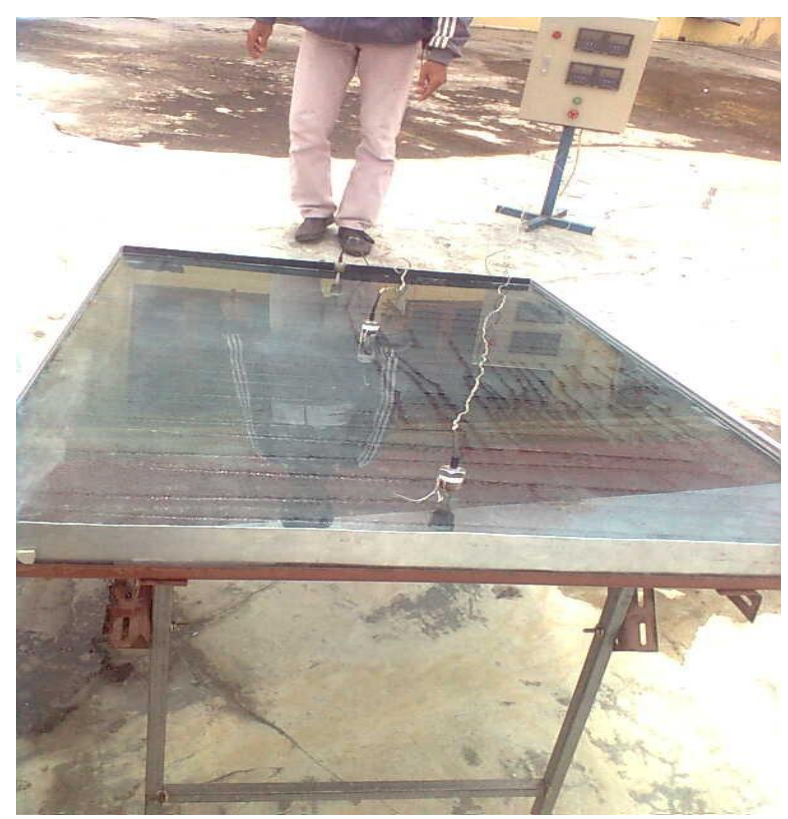

Gambar 4. Proses pengujian dan pengambilan data.

Perpindahan secara radiasi dapat dihitung dengan persamaan [7]

$$
Q=\sigma A\left(T_{1}^{4}-T_{2}^{4}\right)
$$

Dimana :

$\mathrm{Q}=$ Laju perpindahan panas $(\mathrm{W})$

$\sigma=$ Konstanta stefan-boltzmann $5.67 \times 10^{-8}\left(\mathrm{~W} / \mathrm{m}^{2 \circ} \mathrm{K}^{4}\right)$

$\mathrm{A}=$ Luas bidang $\left(\mathrm{m}^{2}\right)$ 


\section{Jurnal Rekayasa Material, Manufaktur dan Energi http://jurnal.umsu.ac.id/index.php/RMME}

\section{HASIL DAN PEMBAHASAN}

Hasil pengujian yang dilakukan dengan kapasitas air laut $3600 \mathrm{ml}$, alat destilasi bekerja dengan baik. Penguapan dan pengembunan terjadi, sehingga dihasilkan air bersih. Gambar 5 menunjukkan butiran-butiran uap air dan air bersih yang dihasilkan.
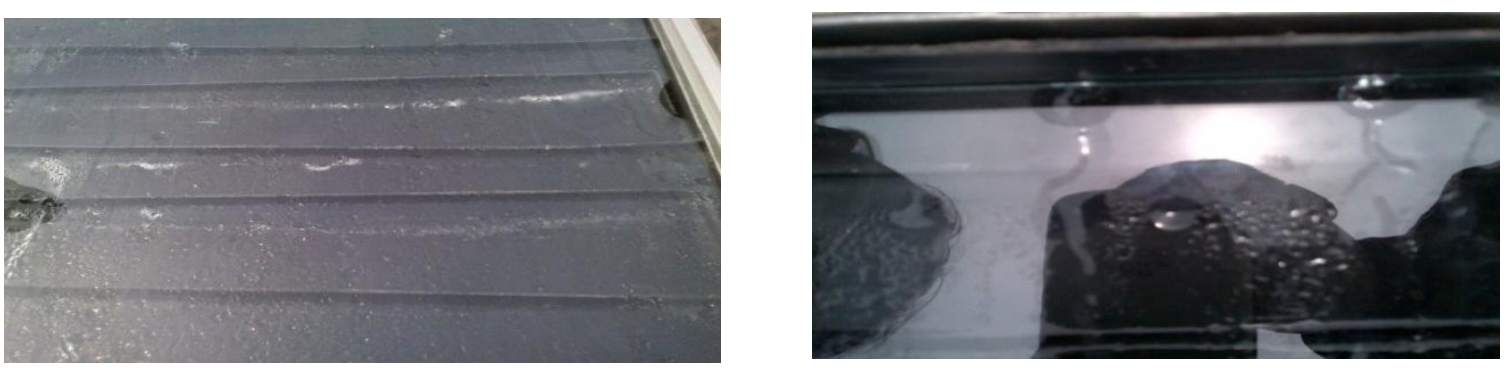

Gambar 5. Butiran butiran air yang menempel pada kaca penutup akibat proses penguapan dan kondensasi.

Dari hasil pengujian diperoleh bahwa produksi air bersih terbanyak dihasilkan dengan kemiringan sudut $30^{\circ}$ sebesar $650 \mathrm{ml}$. Sedangkan kemiringan $40^{\circ}$ sebanyak $645 \mathrm{ml}$ dan pada kemiringan sudut $50^{\circ}$ sebanyak $632 \mathrm{ml}$. Pengambilan jumlah produksi air bersih juga dilakukan pada pukul 11.00 sampai 14.00WIB. Hasil tersebut juga sejalan dengan penyerapan temperatur alat destilasi. Dimana temperatur tertinggi berada pada kemiringan sudut $30^{\circ}$.

Tabel 1. Temperatur pada alat destilasi.

\begin{tabular}{|c|c|c|c|c|c|c|c|c|c|c|c|c|c|}
\hline \multirow{2}{*}{$\begin{array}{c}\text { Jam } \\
\text { (WIB) }\end{array}$} & \multirow{2}{*}{$\begin{array}{c}\mathrm{Ta} \\
\left({ }^{\circ} \mathrm{C}\right)\end{array}$} & \multicolumn{3}{|c|}{$\operatorname{Tg}\left({ }^{\mathrm{O}} \mathrm{C}\right)$} & \multicolumn{3}{|c|}{$\operatorname{Tsv}\left({ }^{\mathrm{O}} \mathrm{C}\right)$} & \multicolumn{3}{|c|}{$\mathrm{Tw}_{1}\left({ }^{\circ} \mathrm{C}\right)$} & \multicolumn{3}{|c|}{$\mathrm{Tw}_{2}\left({ }^{\circ} \mathrm{C}\right)$} \\
\hline & & 30 & 40 & 50 & 30 & 40 & 50 & 30 & 40 & 50 & 30 & 40 & 50 \\
\hline 11.00 & 33 & 34 & 34 & 34 & 34 & 34 & 34 & 34 & 34 & 34 & 34 & 34 & 34 \\
\hline 11.30 & 33 & 43.2 & 42.6 & 41.6 & 47.6 & 47 & 41.2 & 45.7 & 48 & 48 & 45.9 & 48.7 & 47.7 \\
\hline 12.30 & 36 & 56.7 & 54.7 & 54 & 62.6 & 58.4 & 61.2 & 73 & 70.5 & 67.8 & 65.4 & 63.8 & 61.1 \\
\hline 13.00 & 35 & 50.8 & 48.6 & 49.8 & 54.8 & 54 & 55.9 & 56.3 & 57 & 59.7 & 55 & 56.6 & 57.2 \\
\hline 14.00 & 33 & 44.3 & 47.1 & 47 & 47.9 & 53.6 & 53 & 47.9 & 52.3 & 52.4 & 47.9 & 51.2 & 51.6 \\
\hline \multicolumn{2}{|c|}{ Temperatur } & 47.15 & 46.63 & 46.18 & 50.83 & 50.01 & 50.13 & 53.30 & 53.53 & 54.21 & 51.45 & 52.1 & 51.26 \\
\hline
\end{tabular}

Tabel 1 diatas, memperlihatkan, bahwa seluruh bahagian temperatur yang diukur menyatakan penyerapan panas tertinggi terletak pada kemiringan sudut $30^{\circ}$. Hal ini sejalan dengan jumlah produksi air bersih yang dihasilkan.

Berdasarkan pada persamaan 1 diatas, maka nilai perpindahan panas radiasi ditampilkan pada tabel 2. 

http://jurnal.umsu.ac.id/index.php/RMME

Tabel 2. Perpindahan panas radiasi

\begin{tabular}{cccc}
\hline \multirow{2}{*}{ JAM (WIB) } & \multicolumn{3}{c}{ Q radiasi (Watt) } \\
& $30^{\circ}$ & $40^{0}$ & $50^{\circ}$ \\
\hline 11.00 & 6.53 & 6.53 & 13 \\
11.30 & 69.67 & 65.38 & 64,75 \\
12.00 & 137.25 & 128.58 & 112.28 \\
12.30 & 153.06 & 136.95 & 131.38 \\
13.00 & 113.04 & 96.27 & 112 \\
14.00 & 77.6 & 98.15 & 97.41 \\
\hline Q Rata-rata & 92.86 & 88.64 & 88.47 \\
\hline
\end{tabular}

Tabel 2 menjelaskan bahwa, proses perpindahan panas radiasi terbesar ke alat destilasi juga terjadi pada kemiringan sudut $30^{\circ}$.

\section{KESIMPULAN}

1. Alat destilasi air laut tenaga surya yang diteliti dapat digunakan sebagai alat alternatif untuk mengubah air laut menjadi air tawar.

2. Potensi radiasi surya yang paling besar pada jam $12.00 \mathrm{WIB}$ yakni $908,712 \mathrm{~W} / \mathrm{m}^{2}$. Hal ini disebabkan oleh posisi matahari tegak luruh dengan alat destilasi.

3. Variasi sudut kemiringan $30^{\circ}, 40^{\circ}$ dan $50^{\circ}$ pada alat destilasi air laut ternyata berpengaruh terhadap temperatur kaca,ruang basin dan air laut serta kapasitas air tawar yang dihasilkan.

4. Setelah dilakukan penelitian sudut kemiringan $30^{\circ}$ merupakan sudut yang paling efektif dimana temperatur air laut yang didapat yakni $73{ }^{\circ} \mathrm{C}$ pada jam $12.30 \mathrm{WIB}$, laju perpindahan panas radiasi 92,86 Watt per hari serta air tawar yang dihasilkan lebih banyak yaitu $650 \mathrm{ml}$.

\section{DAFTAR PUSTAKA}

[1] Jaisankar S., Ananth J., Thulasi S. Jayasuthakar S.T., and Sheeba, K.N. (2011). Comprehensive Review On Solar Water Heaters. Renewable and Sustainable Energy Reviews (Elsevier), 15 (2011) 3045-3050.

[2] Pratama Adhie Wisnu., Nurdiana Juli., Meicahayanti Ika. (2017), Pengaruh Perbedaan Jenis Plat Penyerap Kaca dan Papan Mika Terhadap Kualitas dan Kuantitas Air Minum Pada Proses Destilasi Energi Surya, Prosiding Seminar Nasional Teknologi IV, eissn 2598 - 7429.

[3] Mulyanef, Burmawi, dan Muslimin K, Pengolahan Air Laut Menjadi Air Bersih Dan Garam Dengan Destilasi Tenaga Surya, vol 4, No 1, 1 April 2014 : 25 - 29

[4] Ward Jhon. (2003), A Plastic Solar Water Purifier With High Output. Solar Energy (Elsevier), 75, 433 - 437.

[5] C.A Siregar, Munawar A Siregar and Sudirman Lubis, (2018). Pengaruh Jarak Kaca Terhadap Efisiensi Alat Destilasi Air Laut yang Memanfaatkan Energi Matahari di Kota Medan. Journal Of Mechanical Engineering, Manufactures, Materials And Energy, Vol 2. p-ISSN : 2549-6220 e-ISSN: 2549-6239

[6] C.A. Bauer, R.A. Wirtz, (2000). Thermal characteristics of a compact, passive thermal energy storage device. Proceedings of the 2000 ASME IMECE, Orlando (Florida, USA).

[7] Holman, J.P. 1995. Perpindahan Kalor, Jakarta: Erlangga 